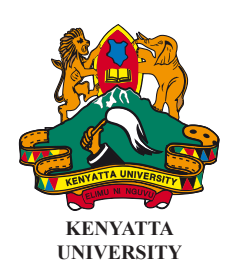

ISSN 1563-1028

\section{CHEMCHEMI}

International Journal of Humanities and Social Sciences

\title{
NARRATING THE KENYAN NATION IN DIFFERENT COLOURS
}

\author{
Jennifer Muchiri
}

\begin{abstract}
At a time like now when the Kenyan nation is undergoing social, economic, political, cultural, and other forms of turmoil, the society needs stories that would help it rethink its identity(ies). The society needs narratives of renewal and hope, but which at the same time seek to restore its humanity. This paper explores the place of literature and literary writers in the discourse on the identity question through a close reading of the novel Different Colours by Ng'ang'a Mbugua. The paper argues that Different Colours is a modern allegory on and of Kenya and the Kenyan society. The image(s) evoked and provoked by the "different colours" of the title, the artists' world in the text and the multiplicity of hues and shades that form the painting at the centre of the narrative recall the attempt to imagine contemporary Kenya. Producing a painting is no different from imagining and constructing a nation out of the different hues of races, tribes, religions, and cultures that is a country like Kenya. This paper, therefore, pursues the argument that Different Colours is a modern tale that creatively plays with the possibilities of imagining and moralising about Kenya as a nation formed out of the diversity of identities that are found within her.
\end{abstract}

Key words: Allegory, Diversity, Nation, Art, Unity, Identity

\section{Introduction}

This paper is a close reading of Ng'ang'a Mbugua's Different Colours (2011) in relation to the salient issues of unity and national cohesion. I make a comparative study of the artistic reflection of nationhood against the reality of suspicion and non-acceptance of the "other." I study the characters in the novel as symbolically representing human beings in the contemporary Kenya and explore how Mbugua creates a narrative that communicates how human beings survive in the face of diversity. In addition, I examine how the narrative reflects the role that art and play in the realisation of national cohesion and social progress. I employ the theory of narratology to demonstrate how Mbugua uses art to mediate the gap between hard facts and the reality of human experiences with regard to otherness. The paper's argument borrows from the tenets of narratology as espoused by Mieke Bal, Gerald Genette, and Seymour Chatman. Their arguments on narrative and discourse aid my analysis and interpretation of the relevance of the story in Different Colours to the making and understanding of the Kenyan nation.

Narratology is basically the study of narrative and narrative structures. It focuses on aspects of the narrative such as story, plot, themes, narrative voice, characters, and setting and explores how the process of narration affects readers' perception of the text. Borrowing from Benedict Anderson's argument about the role of the novel in contributing to the creation of a nation as an imagined community, the paper argues that Mbugua's novel is an allegory of the Kenyan nation. According to Slemon (1988), allegory has traditionally been seen as "a constrained and mechanical mode of expression" (p. 157). Mbugua's use of allegory in Different Colours fits within what both Slemon and Ogude (1999) sees as a "reappropriation" of allegory by post colonial writers so that it is no longer a strategy of communicating for marginalised peoples or communities. Ogude (1999) states that "postcolonial allegory acquires a transformative capacity in its attempt to subvert or challenge the imperial myths and codes that make up the colonised people's notions of received history" (p. 44). Slemon (1988) observes that: 
Allegory provides the postcolonial writer with a means for foregrounding such inherited notions and exposing them to the transformative powers of imagination; and in doing so, post-colonial allegory helps to produce new ways of seeing history, new ways of 'reading' the world (p.164).

In the Different Colours novel, Mbugua employs allegory in this redefined form to communicate his vision for a new Kenya, a nation in which one's colour, race, tribe, age, religion, gender, and other determinants of identity do not get in the way of unity and nationalism.

\section{Different Colours}

Different Colours tells the story of Miguel, the novel's protagonist, a painter who travels to a strange land, Banana County,to paint a famous waterfall. The people of Banana County belong to a different tribe and speak a different language from Miguel and he faces hostility on arrival since the residents of Banana are suspicious of this stranger. After the initial tension of trying to fit in among a people who are different from him, Miguel quickly makes friends and embarks on the task that brought him to Banana County to paint the water fall at Orange River. While touring the area to get an idea of how to go about his task, Miguel discovers that the water fall is under destruction by a wealthy and powerful resident of Banana, Dick Teita, who has employed young men to dig up a quarry on the banks of the river. The danger is that should the digging continue at the quarry, the grounds at the falls would collapse and the entire village will be swept away by the water. Miguel has to sensitize the villagers about the dangers of digging up the quarry while at the same time facing death threats from Dick Teita for interfering with his business. The success of Miguel's presence in Banana County is that he mobilizes help from experts and well-wishers from around the country and even outside the country to save the water fall, and therefore, the people, from destruction. While in Banana County, Miguel falls in love with Angela Tenge, a widow, and becomes a father figure to Tom Tenge, Angela's young son.

Because all these different colours are coming together to form one big and beautiful painting. It is just like our county and our nation. We have people who are so different from each other but they are all part of one nation

(Mbugua, 2011, p. 258).

The above words, uttered, significantly, by Tom Tenge, a child character in Different Colours, underscore the message of the story of love, unity, and acceptance that is Ng'ang'a Mbugua's novel. For Miguel, the colours reflected by the magnificent waterfall create a "permanent rainbow" (p.73) which he tries to capture on the canvas with his brush and paint. The title of the novel derives from the name of the painting, suggested to Miguel by the young Tom Tenge. It is this idea of a rainbow, created by the coming together of different shades and hues, that Mbugua plays on to create an allegory of the contemporary Kenyan nation. In this tale, Mbugua imagines and produces a nation formed within the adage of "unity in diversity" (p. 257) by using the image of different colours to symbolize the differences in race, tribe, gender, religion, socio-economic classes, culture, language and age, which exist in our society.

Miguel travels to Banana County at the instigation of Billy Joe, a sculptor he meets at an artists' colony, where he also meets other kinds of artists "including sculptors, poets and musicians" (p. 4). The idea of a colony of artists relates to the idea of a rainbow and the concept of unity in diversity in the sense that different kinds of artists are able to come together to share ideas, experiences and theories and to express their creativity in different ways. Through the idea of the colony of artists, Mbugua explores the nature of art and the role of art and artists in society. Every kind of art/artist - oral, written, music, painting, sculpting, carving, pottery - has a contribution to make towards the progress of a society and the cultivation of unity among different peoples.

Artists get their inspiration to create from their experiences within the societies in which they live, and their works reflect both the experience and the societies themselves. Commenting on the relationship between a writer and his society, Ngugi wa Thiong'o says in Homecoming that: 
A writer responds, with his total personality, to a social environment which changes all the time. Being a kind of sensitive needle, he registers, with varying degrees of accuracy and success, the conflict and tensions in his changing society... For the writer himself lives in, and is shaped by, history (1972, p. 47).

Although Ngugi's words refer to written art, his argument can be extended to all forms of art and artists. For instance, while Mbugua uses words to bring his story to life, Miguel uses brushes, paint and canvas, and Billy Joe use chisel and wood. The narrative that is Different Colours explores the role of art and the place of artists in society in a bid to communicate the beauty of art but also the significant place it holds in society. The writer reveals art to be a kind of calling; a way of encouraging other artists; a mode of relaxation for readers, viewers, and listeners; and a way of earning a living for the artists. In addition, he presents artists as re-creators and interpreters of the world and people who have the ability to explore the world and present its secrets for the world to appreciate. When Miguel meets Billy Joe at the artists' colony the latter's description of the waterfall is so enchanting that Miguel "developed an itch to seek [it] out and transform it from work of nature into a work of art" (p. 5). He therefore sets off on a journey to paint a magnificent waterfall on Orange River in Banana County.

Mbugua is concerned with the subject of nature and the environmental conservation and, just like in his novella Terrorists of the Aberdare, (2009) he gives prominence to this topic in Different Colours. In the latter novel, Mbugua gives prominence to the waterfall in Orange River, making it the focal point of the narrative, and describing it and the environment around it in such a way that nature integrates itself into the art. Just like Miguel wants to immortalize the waterfall with brushes and paints on canvas, so does Mbugua want to make a case for the environment, through the power of narration.

\section{Allegory of the Journey}

Miguel's journey to paint the waterfall takes him from Ilovi, the part of the country where he lives and is familiar with, to Banana County, a strange part the country where he is treated with suspicion as soon as he lands. In Mbugua's narrative of modern Kenya, Miguel's journey becomes an allegory of change of attitudes and perceptions. It is an indicator of the need for a society or nation to make a journey towards a new nation that treats all people justly regardless of their clan, race, tribe, gender, religion, culture, class, language, or other identifying aspects.

Geographical regions are an important site or field of identity formation and one's place of origin therefore often informs who they are and how they relate with others. In this narrative, the concept of journeying underscores the role of movement from one place to another, meeting and understanding the "other" in contributing to national cohesion and consequently the construction of a nation. For instance, the narrator explains that Taidora's father, Fadhili, was born and brought up in Mashariki County but "had been posted as a District Commissioner to Kusini as part of a government programme to foster understanding between the people of different regions" (p. 8). Fadhili does not fit into his new community easily as the native "owners" of the region "considered him a foreigner who had taken away their land and was lording it over them" (p. 8) a statement that has undertones of tribal relations in Kenya. Just like Fadhili, Miguel's arrival in Banana is not received kindly by some residents. They treat him with suspicion and they are initially wary about his presence.

The suspicion with which the residents of Banana County treat Miguel, a stranger, is heightened by the fact that he sports dreadlocks, which they associate with criminals and drug abusers. Thus, even after he has told them his name, they insist on calling him Rasta or Rastaman, insistence which indicates their 
reluctance to accept a stranger. A name is the primary mark of a person's identity and these people's sustained refusal to call Miguel by his name clearly reveals that they do not acknowledge him as part of their society. Their judgment of Miguel's character based on his hair style alone indicates the misconceptions that society holds about other people simply because they look different or come from a different region and therefore possess different cultures. "To them, he was a stranger and he did not know their ways" (p. 16).

When Miguel, soon after arriving in Banana town, insists on travelling in comfort and refuses to move for an extra passenger in the old taxi, the only means of transport available, the taxi driver is shocked at the impertinence of the stranger:

\section{Go? Did you just say go?}

Is there something wrong with you Rastaman? Do men in your village leave women stranded by the roadside? By the way [emphasis added], where do you come from? Don't people in your part of the country have respect for women and the aged? (p. 17)

The taxi driver's words, all uttered in the form of rhetorical questions, are an indictment on the culture and mannerisms of the "other" often stemming from ignorance and fear that the other is encroaching on our space. For the taxi driver, the origin of Rastaman is inconsequential (a by-the-way); the key issue is that he is not one of them.

The altercation with the taxi driver is the first of several challenges Miguel will face in his journey to the mysterious waterfall. His arduous walk from the town, after choosing to walk rather than travel in an overcrowded taxi, is symbolic of the challenges society faces while on the journey to national cohesion. It takes him over one hour of walking in the hot afternoon sun along a dusty and winding road to get a place where he can rest. Just like the residents of Banana County regard him as a stranger, he too thinks that "they are far from hospitable" (p. 19). Miguel, however, does not stop at noticing the differences between him and Banana County residents; he makes a conscious decision to "tread carefully" (p. 18) so that he can achieve his mission in the strange land and he even begins to "lay out survival strategies, complete with a plan on how he would treat the next person he met" (p. 19). Miguel's decision indicates that members of the society have to consciously make a decision; a choice to understand and accept others who may be different from them. When he makes this decision, Miguel finds it easy to speak to the next group of Banana County residents that he meets and within a short while he not only has a landlady and a friend, Angela, but is able to get leads towards his mission in the village - the water fall. It is this friendship that leads not only to the inspiration to paint the waterfall, but it culminates into a discovery of love.

\section{Charactonyms and Naming of Places}

Mbugua's choice of names for the characters and places in the novel contributes significantly to the narrative of constructing the Kenyan nation. A person's name is the primary signifier of their identity and people can identify a person's origin - tribal, racial, national - purely on the basis of a name. Leigh Gilmore in Autobiographics: A Feminist Theory of Women's Self Representation, arguing about the importance of a name in a different context, says that "it identifies a person within a historical context of place and patrilineage, and focuses attention on the solid corporeality to which it refers. Ultimately, it seems to mark a ground zero of representational veracity" (1994, p.65). The names of characters in Different Colours are such that they cannot be directly linked to a particular geographical region or specific ethnic group in Kenya.

The protagonist, Miguel, whose original name is Michael, can easily live in any part of the nation and not be identified as belonging to a specific community. He, like most of the characters in the novel has only one name. Thus Miguel, Angela, Derek, Zebedayo (an African corruption of the Biblical Zebedee), Tobby and Juliana cannot, in Gilmore's words, be identified within a context of place and patrilineage; they play 
a representational role. Their names are symbolic of the need for unity as opposed to the disunity that may arise from differences in ethnic or geographical origins.

Mbugua also employs charactonyms for some of the characters in the novel. Fadhili, the name of the District Commissioner for Kusini, is Kiswahili for kindness or compassion, while Vu Tabangi is a coinage from vuta bangi, Kiswahili for the act of smoking bhang, and is an explicit statement on the character of Vu Tabangi, one of the thugs who attack Miguel and kill Martin Tenge. Dick Teita is a corruption of "dictator" and a commentary on the personality of this character, the novel's villain. Inspector Yusuf's name, Kachero, is Kiswahili for 'detective,' and therefore a commentary on the kind of work he does. These characters, therefore, are representative of people from various tribes, cultures, and races that live in the world created by the writer and therefore form the collage or multiplicity of people's and identities that is the nation.

The names of places in the novel are also representative as opposed to real places that can be identified on a map. Mashariki, Kusini, Kaskazini, Magharibi are named after the four cardinal compass points - East, South, North and West respectively - again, in Kiswahili, as are the names Matunda and Poromoko. Kiswahili, one of the two official languages in Kenya has for a long time been the national language and therefore one of the nation's unifying factors. The choice of Kiswahili as the language of naming some characters and places is the writer's way of communicating the need for national unity despite the diversity that exists along the lines of tribe, race, nationality, or place of origin. It should be noted that what Mbugua is doing in Different Colours is not necessarily new. A number of the first generation of Kenyan writers employed a wide range of words and phrases borrowed from their languages. For example, Ngugi wa Thiong'o's prose borrows heavily from his Gikuyu language, Grace Ogot's fiction is replete with Dholuo words and expressions and Henry Ole Kulet's novels are rich in words from the Maa language. The difference is that while these other writers were interested in ethnonationalism, Mbugua is sending a message of supra-nationalism.

The Orange River, on which the waterfall exists, gets its name from one of the brightest colours of the rainbow. The colour, which implicitly relates to the name of the painting that will eventually capture the beauty of the waterfall on the canvas and the title of the novel, is the colour of the rising sun, a symbol of hope. Different Colours being a narrative of hope and renewal, the river and the waterfall are symbolic of hope and life for the nation for as long as her different peoples, just like the various rivulets that form the river and the fall, live in harmony. On the other hand, the Orange River and the waterfall, which are part of the environment or nature, could lead to death if they are not nurtured and protected. Mbugua's choice of the river to symbolize the dichotomy of life and death is significant because water gives life but can also cause death and destruction through floods. The symbol of the river is a common element in Kenyan literature. It has been used quite effectively in Ngugi wa Thiong'o's The River Between and Margaret Ogola's The River and the Source to communicate a wide array of issues.

When the residents of Banana County discover that Dick Teita, Vu Tabangi and others are destroying the rocks which hold the waterfall and could eventually lead to the destruction of the entire village, they take action to protect the river and the waterfall. The river has been part of their lives and has contributed to their existence in various ways: a source of firewood and water for bathing and washing clothes; herding and watering livestock; romantic liaisons; swimming; circumcision rituals, hiding place for the freedom fighters (the caves); and earnings from the occasional tourists. The need to protect the river and the waterfall from the greed and exploitation is symbolic of the need to protect the bonding qualities that hold us together as a nation. Ironically, it is through Vu Tabangi's stream of consciousness that we get to know about some of the roles that the waterfall plays in the lives of the residents of Banana County.

Vu Tabangi works for Dick Teita at the quarry near the fall out of ignorance. Until John explains to him the danger and the consequences of what he has been doing, Vu Tabangi has no idea that by digging at the quarry he is endangering his life and those of his family and neighbours. Vu Tabangi is a bhang smoker, a thug and a murderer, but his realization that his work at the quarry poses a danger for his people and his eventual confession to the murder of Martin are a statement on the possibility of redemption and 
restoration of humanity in the narrative. He aids in the arrest of Dick Teita, the symbol of greed and exploitation in the narrative and in the process, although he too is arrested as part of the delivery of justice, $\mathrm{Vu}$ Tabangi receives some empathy from the reader. Vu Tabangi is, therefore, a symbol of part of our society that contributes to exploitation and violence out of ignorance and manipulation by leaders or citizens who hold positions of power and wealth.

\section{Unity}

Just like the river is a unifying factor for the residents of Banana County, young and old, male and female, and from different religious affiliations, Mbugua underscores the need for the nation to come together and take advantage of that which unites us as opposed to focusing on our differences. Miguel and Derek, who are non-natives of Banana County, and who would be treated with suspicion on account of their being "strangers" are ironically, the ones who not only discover the wanton destruction that is going on at the waterfall, but they take a leading role in hunting down Dick Teita and seeking ways of protecting the important resource that is the river and its waterfall. Due to their efforts, the Banana Community comes together for a noble cause, to protect the waterfall and, in extension, the environment, a statement on what a nation can achieve if the people are united. Miguel and Derek's efforts to create and raise awareness on the imminent destruction of the waterfall through the internet and mainstream and social media lead to the arrival of the Flora and Fauna Fund, led by Rudolf Gottfried and Aiko Hiyedoshi, an organization whose "work is to help people who want to preserve their environment from destruction caused by unchecked exploitation" (p.203). Just like Miguel and Derek, Gottfried and Hiyedoshi are foreigners in Banana County; in fact they come from two different continents, Europe and Asia, and therefore belong to different races altogether. Yet, it is they who eventually introduce new ideas and ways of thinking in Banana County when they find a company that runs environmentally friendly hotels and is interested in starting one in the village. The understanding is that $30 \%$ of the earnings would remain in the village and the tourist industry will create employment and business opportunities for the residents.

Miguel, Derek, Gottfried and Hiyedoshi are representative of the culture, tribe, race, language of "other" and Mbugua assigns leading roles in the preservation efforts to them to emphasize the need to accept and appreciate other people because each one of us has a role to play in the progress of the nation. Their presence in the village is an indicator of the change that the village is about to experience, which, through the narrative, Mbugua presents as a necessary evil in the construction of a new nation. The villagers agree with Gottfried that change and integration of different kinds of people will bring about some challenges but they are prepared to face these as they replace the old order with a new a one for the progress of their society.

When the villagers decide to choose a team of representatives to represent them in the negotiation with the hotel company, they do so in the open, an implicit statement on the need for transparency in choosing a nation's leaders. The team, comprising of Zebedayo, Angela, Juliana, Tobby and Wendo, brings together a diversity of gender, age and religion. The members of the team are a statement on the need to involve all sections of the society in decision making. In addition, the team is reflective of unity and the realization that each member of the society has a role to play in the development of the nation regardless of whom they are or where they come from. To indicate their change of attitudes and perception regarding strangers or people who possess a different culture, the people of Banana County embrace Derek, Miguel, Gottfried and Hiyedoshi as their advisors thus adding to team's diversity an element of tribe and race. In this way, the group that will spearhead this village's journey towards a new dawn is one founded on friendship, acceptance, unity and hope. Clearly it is a team that embraces the concept of unity in diversity. The coming together of these people reflects Mbugua's vision for the new nation, captured clearly in Miguel's thoughts when he first arrives in Banana County:

We have to build an open society...If we are to progress, we must be ready to embrace new people, we must be able to look them in the eye and feel comfortable around them no matter how different their ideas may be from our own. (p. 122) 
Mbugua compares distrust, suspicion, hatred and rejection of other people's ways to "a cold wind [which was] picking up, blowing silently through the land" (p. 177). The image of a cold wind indicates how suspicion of strangers of people who are different from us can develop and spread among the people, giving way to tension, violence and ultimately, destruction of the nation. This kind of suspicion and hatred is such that it happens right from the family level where parents reject prospective sons or daughters-in law who come from different cultures as happens in Angela's case. If not checked, such family conflicts easily lead to national conflict.

\section{The Painting as an Allegory}

It is only after the people in Banana County have shed their suspicion of strangers and embraced people from other regions that "The Painting" can finally take shape. At the encouragement of Angela, Miguel finally gets the inspiration to put brush on canvas. The painting is a collage of different colours: blue, white, brown, yellow, sepia, gray, green, brilliant red, and orange (p.169). The different colours are allegorical of different peoples, cultures, races, tribes, religions, gender, ages, social-economic classes that for the collage that is the imagined nation in Mbugua's narrative. Just like the painting is a collage of colours, the nation is a collage of different peoples and cultures working together to form a complete whole.

Looking at the painting, Miguel feels that "it was the closest he could have got to heaven" (p. 169). The image of heaven (paradise) is a statement on the concept of hope and restoration for the nation. The narrator's description of the painting is so vivid that we feel like we are looking at it. In Narratology: Introduction to the Theory of Narrative (2009) Mieke Bal argues that "Description is a privileged site of focalization, and as such it has great impact on the ideological and aesthetic effect of the text" (p. 35). The narrator's description of the painting not only contributes to the aesthetics of the story but it also concretizes the author's concerns and leaves a lasting impression on the readers' minds. What the painter captures with brushes and colour/paint, the writer does it in words.

By the end of the narrative, even Billy Joe has returned home, albeit briefly, indicating that he too, is part of the new nation. The complementarities of art, which Mbugua alludes to throughout the narrative, are a statement on the role of art and artists in constructing a nation. Angela's proposal that Miguel name his painting "The Painting that Changed a Village" (p. 257) also points to the role of art and artists in effecting change in society. Miguel's desire to paint a waterfall, an important part of the environment in Banana County ends up causing hitherto unimaginable change in the little village.

Tom Tenge's proposal for the name of the painting, "Different Colours" (p. 258), which also gives the narrative its title, is significant because the idea of a collage of different peoples is communicated through the voice of a child. Writing about the importance of children as narrators and characters in literature in The Child Narrator: George Lamming's In the Castle of My Skin (2010) I argue that narratives allow us to observe as children "hatch from the world of purity, naivety, and innocence, to the enslaving world of adulthood and sense" (p. 25). Children are often innocent and bear no prejudice against other people, but the experience of adulthood and the complexities of the adult world often strip them of their innocence. Tom Tenge's unconditional acceptance of Miguel as a father figure, to the extent of calling him "uncle," is an indication of the innocence of children in the sense that he loves Miguel regardless of the fact that he is a "stranger." The wisdom carried in the explanation he gives for the name of the painting makes him a symbol of hope and renewal for the nation. Indeed, the young boy enables us to see Mbugua's vision for a new nation and calls on the nation to engage in a process of both introspection and retrospection with regard to the creation of a united Kenya. He is the voice of reason and a call for unity and the restoration of humanity in the new nation. 


\section{Conclusions}

The narrative of Banana County can be read as allegory of modern Kenya, a nation that is seeking to reconstruct and identify itself as a collage of the different shades and hues of tribes, races, religions, social-economic classes, cultures and other differences that exist alongside each other. For Miguel, Banana County "was the whole nation congealed. The good was as prominent as the bad; the beautiful stood side by side with the ugly, and love had its corner next to hatred; acceptance and rejection were constant companions" (p. 229). Miguel's words point not only to the diversity that exists in society and the quality of life, but also to the fact that regardless of the diversity in our cultures, human values and experiences are largely similar. Banana County therefore is a pun on the kind of a nation a republic would become (a banana republic) if the citizens allow themselves to be divided along ethnic, racial, religious or other lines.

Miguel's journey to Banana County enables him to encounter suspicion, greed, exploitation, rejection, violence, justice, acceptance, love, reconciliation and healing. By the end of the narrative, he has not only completed his painting and therefore achieved his mission in Banana County, but he has also found love in what he refers to as "this beautiful land of peculiar people" (p. 260). The union between Miguel and Angela, a love story that is not explicitly narrated, is symbolic of the coming together of different peoples in the nation. Their union is an indication of a new dawn in human relations within the nation and they, symbolically, seal the deal of acceptance, peace and unity with a kiss, a symbol of intimacy.

Different Colours, therefore, is an examination and commentary of human relations; a call for the re-evaluation of our values as a nation; and a creative construction of the idea of unified communities. In the move towards achieving cohesive communities, Mbugua makes a statement on the need for art - written, oral, visual, or performed - to work without borders too and serve its function(s) in the society.

\section{References}

Anderson, B. (1983). Imagined communities: Reflections on the origin and spread of nationalism. London: Verso.

Bal, M. (Ed.). (2009). Narratology: Introduction to the theory of narrative, 3rd ed. Toronto: University of Toronto Press.

Chatman, S. (1978). Story and discourse: Narrative structure in fiction and film Ithaca: Cornell University Press.

Genette, G. (1980). Narrative discourse: An essay in method. Ithaca: Cornell University Press.

Gilmore, L. (1994). Autobiographics: A feminist theory of women's self representation. Ithaca, New York: Cornell University Press.

Mbugua, N. (2011). Different colours. Nairobi: Big Books.

Mbugua, N. (2009). Terrorists of the Aberdare. Nairobi: Big Books.

Muchiri, J. (2010). The child narrator: George Lamming's In the Castle of My Skin. Saarbrucken: VDM Verlag.

Ngugi wa Thiong'o. (1972). Homecoming: Essays on African and Caribbean literature London: Heinemann.

Ogude, J. (1999). Ngugi's novels and African history: Narrating the nation. London: Pluto.

Slemon, S. (1988). "Post-colonial allegory and the transformation of history." Journal of Commonwealth Literature, 32:1, 157-81. 
About the Author

Dr. Jennifer Muchiri is a faculty in the Department of Literature, University of Nairobi, Kenya. 